\title{
Rhabdoid tumor
}

\author{
INSERM
}

\section{Source}

INSERM. (1999). Orphanet: an online rare disease and orphan drug data base. Rhabdoid tumor. ORPHA:69077

Rhabdoid tumor (RT) is an aggressive pediatric soft tissue sarcoma that arises in the kidney, the liver, the peripheral nerves and all miscellaneous soft-parts throughout the body. RT involving the central nervous system (CNS) is called atypical teratoid rhabdoid tumor (ATRT; see this term). 